\title{
The Route of Mycotoxins in the Grape Food Chain
}

\author{
Ana Gonçalves, ${ }^{1}$ Roberta Palumbo, ${ }^{2}$ Ana Guimarães, ${ }^{1}$ Athanasios Gkrillas, ${ }^{3}$ \\ Chiara Dall'Asta, ${ }^{3}$ Jean-Lou Dorne,${ }^{4}$ Paola Battilani, ${ }^{2}$ and Armando Venâncio ${ }^{1 *}$
}

\begin{abstract}
Grapes are consumed throughout the world in different ways, ranging from fresh fruit to processed products. Regardless of the product, risk management starts in preharvest stages to control initial development of mycotoxigenic fungi and avoid consequent problems in the whole chain. The main concern in grapes and grape products is the presence of black Aspergillus species and the subsequent production of ochratoxin A. However, other mycotoxigenic fungi have been detected and may need further attention. The adoption of crop management strategies, such as selection of varieties, training system, and soil management, can reduce fungal proliferation. Biological methods can also be used to inhibit fungal contamination. These methods can substitute for chemical approaches and be used in later phases of grape processing to allow safe storage. Due to the wide range of products that can be obtained from grapes, different fungal species can be responsible for postharvest deterioration. Taking this into account, the aim of this work is to review strategies for mitigation of mycotoxin risk in the whole grape chain considering data on the occurrence and development of mycotoxigenic fungi and mycotoxin biosynthesis.
\end{abstract}

Key words: aflatoxin B1, dried grapes, grape juice, mycotoxigenic fungi, ochratoxin A, wine

Yeasts and lactic acid bacteria are thought to account for the majority of grape microbiota, mainly because of their role during storage and processing. However, filamentous fungi should also be considered because these microorganisms are a threat to the quality of grapes and cause deterioration of sensorial properties. Several species can be responsible for mycotoxin production. Mycotoxins are toxic secondary metabolites that can cause several health problems when ingested, even at low concentrations.

In general, when assessing the risk of contamination in a food product chain, the external conditions in the field such as the environment, the associated fungal load of the soil, pests, possible interactions with other microorganisms or plant diseases, intrinsic factors related to the substrate itself (e.g.,

${ }^{1} \mathrm{CEB}$ - Centre of Biological Engineering, University of Minho, 4710-057 Braga, Portugal; ${ }^{2}$ Università Cattolica del Sacro Cuore, Faculty of Agriculture, Via Emilia Parmense 84, 29100 Piacenza, Italy; ${ }^{3}$ Università degli studi di Parma, Via Università 12, 43121, Parma, Italy; and ${ }^{4}$ European Food Safety Authority (EFSA), Via Carlo Magno 1A, 43126 Parma, Italy.

*Corresponding author (avenan@deb.uminho.pt)

Acknowledgments: This review was prepared as part of MYCHIF EFSA project (GP/EFSA/AFSCO/2016/01). Roberta Palumbo carried out this work within the PhD school Agrisystem of Università Cattolica del Sacro Cuore (Italy). This study was supported by the Portuguese Foundation for Science and Technology (FCT) under the scope of the strategic funding of UID/BIO/04469/2019 unit and BioTecNorte operation (NORTE-01-0145-FEDER-000004) funded by the European Regional Development Fund under the scope of Norte2020 Programa Operacional Regional do Norte.

Manuscript submitted May 2019, revised Nov 2019, accepted Nov 2019

Copyright $(2020$ by the American Society for Enology and Viticulture. All rights reserved.

By downloading and/or receiving this article, you agree to the Disclaimer of Warranties and Liability. The full statement of the Disclaimers is available at http://www.ajevonline.org/content/proprietary-rights-notice-ajev-online. If you do not agree to the Disclaimers, do not download and/or accept this article. doi: 10.5344/ajev.2019.19039 variety differences or nutritional composition), and practices at the field and processing levels must be considered (Khalesi and Khatib 2011).

Fungal contamination begins in the field, and it is in the field where it is most relevant. The susceptibility of berries to fungal parasites is generally a result of conducive environmental conditions and inappropriate phytochemical applications (Barata et al. 2012). Additionally, berries may bear microfissures and soften with ripening, which increases nutrient availability and allows further contamination by fungi. The genera Alternaria, Aspergillus, Cladosporium, Fusarium, and Penicillium are the most frequently reported grape contaminants (Rousseaux et al. 2014). Cropping management allows for proper control of contaminations, and good manufacturing practices during handling and processing can be crucial to the safety of the final products. Nevertheless, the occurrence of fungi and their mycotoxins is unavoidable. For this reason, regulations in the EU set limits for mycotoxins, namely aflatoxins (AFs), ochratoxin A (OTA), and patulin (PAT), in different grape products (Table 1).

Processing of grapes includes several steps that can be adapted to reduce contamination risk. Thermal processing cannot assure a proper elimination or reduction of mycotoxins due to their thermal stability. The combination of temperature with physical treatments, such as pressure, can be effective for eliminating mycotoxins; however, it can have a negative impact on the organoleptic characteristics of the final product (Shukla et al. 2017).

The strategies to control mycotoxins can be applied in several stages of processing and can consist of several different methods. The demand for more natural products has increased attention to the application of naturally occurring antifungal compounds. Biological approaches that take advantage of the competitive abilities of antagonistic microorganisms in the field or during processing can be used to inhibit mycotoxin production. 


\section{Mycotoxin-Producing Fungi in Grapes}

Aspergillus spp. in grapes and mycotoxin production. Fumonisin B2 (FB2) and OTA are the mycotoxins most often detected in grapes; however, AF produced by Aspergillus flavus can also be present (Rousseaux et al. 2014). The main species responsible for OTA production in grapes is Aspergillus carbonarius, but Aspergillus ochraceus and Aspergillus niger can also be found, with the last being the most frequently isolated (Serra et al. 2003, Battilani et al. 2006, Amezqueta et al. 2012, Lasram et al. 2012, Somma et al. 2012, Rousseaux et al. 2014). The biosynthesis of OTA involves polyketide synthase genes present in producers, is largely correlated with the size of a fungal colony and amount of biomass, and can be stimulated by the presence of other fungal species (Magan et al. 2010, Storari et al. 2010, Lappa et al. 2015). Studies on the influence of grape maturation stage on OTA levels demonstrated that OTA accumulation starts at the beginning of maturation (Serra et al. 2006), perhaps as a result of reduced skin thickness that enables fungi to grow inside the berries (Amezqueta et al. 2012, Lasram et al. 2012, Somma et al. 2012). The production of FB2 in grapes is mainly related to contamination with A. niger (Logrieco et al. 2011). Abrunhosa et al. (2011) found that of the 597 strains of $A$. niger aggregate previously isolated from winegrapes, nearly $29 \%$ were FB2 producers, while only $5 \%$ were OTA producers. However, the amount of FB2 produced was low, and the same study showed that no significant correlation exists between OTA and FB2 production, with both toxins produced by only $1.7 \%$ (10 strains) of the 597 strains studied.

The presence of $A$. carbonarius and $A$. niger in grapes results from their presence in the soil under grapevines and can be triggered by agronomic practices that allow them to reach the plant (Khalesi and Khatib 2011, Amezqueta et al. 2012). The infection of grapes by Aspergillus species can cause Aspergillus black rot, a severe disease that causes significant crop loss. Because the fungal load is often present on the surface of grapes, the infection process starts with the entrance of the fungi into the fruit promoted by damage in the skin caused by other fungal attacks, pests, or weather events, which also provide the appropriate moisture and sugar levels for mycotoxin production (Khalesi and Khatib 2011,
Amezqueta et al. 2012, Somma et al. 2012). This assumption was confirmed since skin inoculation of grape berries with A. carbonarius did not cause rot symptoms or OTA production unless previous damage was present on the surface of fruits (Jiang et al. 2013). In addition, experiments aiming to compare the fungal development on grape-based culture medium, grape skins, or flesh have concluded that the flesh is the most suitable for spore germination of $A$. carbonarius, indicating that the fungal attack is much more effective when the interior parts of the fruit are exposed (Camardo Leggieri et al. 2014).

Differences between grape varieties influence the spread of fungal contamination. Cluster compactness can play a role in fungal disease because infection can spread more easily when the fruits are contacting each other (Chiotta et al. 2013). An increase in acidity and a reduction in sugar and soluble solids levels is observed during infection, confirming the assumption that OTA biosynthesis is higher at reduced $\mathrm{pH}$ (Lasram et al. 2012, Jiang et al. 2013). Battilani et al. (2004) tested the susceptibility of the main Italian grape varieties to $A$. carbonarius infection and OTA production. Some varieties (e.g., Cabernet Sauvignon, Trebbiano, and Verdeca) were found to be more susceptible to contamination than others (e.g., Bianco d'Alessano, Pampanuto, and Uva di Troia), but the susceptibility was not correlated with cluster characteristics of each variety. Instead, a natural defense mechanism against infection may take place and influence fungal growth and OTA production. Infecting berries of Vitis vinifera L. cv. Barbera (disease susceptible) and the interspecific resistant variety Castor at veraison with $A$. carbonarius induced stilbene-synthase gene expression and led to production of stilbenes in both varieties, but at a significantly higher rate in the resistant variety (Vezzulli et al. 2007). The induction of trans-resveratrol is common in other black Aspergillus species and is concomitant with fungal growth inhibition (Bavaresco et al. 2003). However, OTA production was induced in synthetic must medium, and a much higher trans-resveratrol concentration was required for inhibition of OTA (Bavaresco et al. 2003). The production of trans-resveratrol appears to be a defense mechanism against A. carbonarius contamination after fungal infection is settled, since an inhibition of OTA production is observed when adequate levels of trans-resveratrol are produced at the initial

Table 1 European Union Regulation on the acceptable amount of mycotoxins in grape products (consolidated European Commission 2006).

\begin{tabular}{|c|c|c|}
\hline Grape product & Mycotoxin & $\begin{array}{l}\text { Max. levels } \\
(\mu \mathrm{gg} / \mathrm{kg})\end{array}$ \\
\hline \multirow[t]{2}{*}{ Dried vine fruits to be subjected to sorting or other physical treatment } & Aflatoxin B1 & 5 \\
\hline & Total aflatoxins & 10 \\
\hline \multirow{2}{*}{$\begin{array}{l}\text { Dried vine fruits and processed products thereof intended for direct human consumption or use } \\
\text { as an ingredient in foodstuffs }\end{array}$} & Aflatoxin B1 & 2 \\
\hline & Total aflatoxins & 4 \\
\hline Dried vine fruit (currants, raisins, and sultanas) & Ochratoxin A & 10 \\
\hline $\begin{array}{l}\text { Wine (including sparkling wine, excluding liqueur wine and wine with an alcoholic strength of } \\
\text { at least } 15 \% \text { by volume), fruit wine, and grape juice }\end{array}$ & Ochratoxin A & 2 \\
\hline Fruit juices, concentrated fruit juices as reconstituted, and fruit nectars & Patulin & 50 \\
\hline
\end{tabular}


stage of infection (De Rossi et al. 2012). In fact, plants produce such phytoalexins as a response to fungal attack, but the interaction with the plant includes the production of enzymes by the pathogen to degrade phytoalexins (Flamini et al. 2016).

The composition of berries also influences colonization and mycotoxin production. Malic and tartaric acids are the major acids in grape musts. Atoui et al. (2007) studied their influence on OTA biosynthesis by A. carbonarius and found that malic acid favors mycotoxin production, while tartaric acid has the opposite effect.

Role of environmental conditions/climate change. Generally, contamination of vineyards by Aspergillus spp. is associated with hot and wet environmental conditions, but the conditions for fungal growth and mycotoxin production are different (Rousseaux et al. 2014). Studies evaluating the influence of minimum and maximum temperatures (to illustrate field conditions during night and day, respectively) showed that hot days promoted fungus growth, whereas cooler nights increased OTA production by Aspergillus species, with the range of 20 to $30^{\circ} \mathrm{C}$ resulting in the highest rate of both parameters for A. carbonarius (Chiotta et al. 2013, Barberis M et al. 2014). Generally, $30^{\circ} \mathrm{C}$ seems to be the optimum temperature for $A$. carbonarius to produce OTA, while incidence of fungal contamination in the field is dependent mostly on temperature and irrigation and less on precipitation (Jiang et al. 2013, Barberis M et al. 2014). The differences in temperatures between regions can influence OTA contamination, as a study in Italy concluded that the incidence of the toxin decreases in the northern parts of the country (Lucchetta et al. 2010). In Spain, a study evaluating the incidence of black Aspergilli species in two different regions demonstrated that a hotter climate favors the presence of these species and OTA contamination (Garcia-Cela et al. 2015). A study in Portugal showed a higher incidence of ochratoxygenic strains in regions with a Mediterranean climate, which is characterized by hot and dry summers, although the increase in OTA incidence was insignificant (Serra et al. 2003).

Considering OTA presence under climate change scenarios, $30^{\circ} \mathrm{C}$ is the limit of temperature above which there is an increased risk, whereas conditions below $21^{\circ} \mathrm{C}$ can be considered safe. For moisture, both wet and dry conditions can pose a threat because of the different water activity $\left(a_{w}\right)$ requirements of different OTA-producing species (Paterson and Lima 2011). Since global warming may shift the distribution of temperature and precipitation patterns, with an increase in exceptionally unfavorable years for several crops, modeling can be useful for the construction of a prediction tool if meteorological data are available and help in vineyard planning and management. Therefore, a predictive system for OTA risk in grapes-OTA-Grapes - was proposed (Battilani and Camardo Leggieri 2015).

With climate change, infection of grapes by black Aspergilli under low water availability and higher temperatures may become dominated by Aspergillus tubingensis and A. niger in detriment of $A$. carbonarius, as well as A. ochraceus, in places where they are now the predominant species (GarciaCela et al. 2012, 2014). This scenario may lead to a reduction in OTA contamination of grapes but to a higher incidence of FB2 in Europe (Garcia-Cela et al. 2015). In temperate regions, AF may also become a greater concern (Paterson and Lima 2010). In cooler regions, the presence of black Aspergilli in general is expected to increase (Storari et al. 2012). However, research on the effect of predicted climate change on mycotoxin occurrence is still scarce, and more knowledge is needed to construct better models that can help predict the variations in mycotoxin contamination and take action more efficiently (Paterson et al. 2018).

Other mycotoxigenic fungi in grapes and mycotoxin production. The genus Penicillium also appears to be responsible for OTA contamination. Several Penicillium species can contaminate grapes, with Penicillium verrucosum playing a more active role in the presence of OTA (Amezqueta et al. 2012). Penicillium spp. in grapes are generally associated with dry climates and lower temperatures, with the requirements of $P$. verrucosum for OTA biosynthesis associated with cooler or more temperate regions (Amezqueta et al. 2012, Rousseaux et al. 2014). Even so, the Penicillium spp. populations are diverse and vary between different regions, with Penicillium brevicompactum and $P$. verrucosum being the most frequent contaminants of vineyards (Rousseaux et al. 2014). Also, PATand citrinin-producing species can contaminate grapes to a lesser extent. In fact, the presence of Penicillium expansum has already been reported in Portugal, Chile, Slovakia, and Hungary (Abrunhosa et al. 2001, Diaz et al. 2011, Felsociova et al. 2015a, 2015b, Tancinova et al. 2015).

The interaction of $P$. expansum with other fungal species can affect its development as well as PAT production. In vitro experiments indicate that Botrytis cinerea, which is frequently present in grapes, is a strong competitor with $P$. expansum, as it decreases its own development time and PAT contamination by metabolizing the toxin (Morales et al. 2013). However, several authors reported that, in the presence of specific $B$. cinerea strains, $P$. expansum produces geosmin, which is thought to play a role in the competition with other fungal species and cause organoleptic deterioration. Geosmin increases $P$. expansum colonization and consequently, mycotoxin production (Paterson et al. 2007, Barata et al. 2012). Morales-Valle et al. (2011) found that $46 \%$ of the assessed $B$. cinerea strains induced geosmin production by $P$. expansum, and their ability to do so was dependent on the medium (white or red grape broth).

Although not the major problem in grapes, contamination with Fusarium was confirmed with the development of fruit rot disease caused by Fusarium avenaceum in Vitis amurensis after 7 days of conidial inoculation (Wang et al. 2015). When studying the infection process of Fusarium spp. during grape drying and after a 24-day inoculation period, half of the total grape area appeared to have necrotic lesions, and aerial growth of the mycelium was observed under favorable conditions (Lorenzini and Zapparoli 2015). The infection of grapes with Fusarium spp. constitutes a risk due to the wide range of mycotoxins produced by the species of this genus. Fusarium proliferatum, Fusarium sporotrichioides, Fusarium oxysporum, and Fusarium verticillioides are among the 
species most often found in assessments of Slovakian grapes (Mikusova et al. 2010, Mikusova et al. 2013, Maskova et al. 2014). The ability of these species to produce mycotoxins like beauvericin or fumonisins, HT-2 toxin, or T-2 toxin is relevant when considering possible contaminations.

Despite the absence of regulation of Alternaria mycotoxin levels, their presence in grapes is a matter of concern, with numerous observations of mycotoxigenic Alternaria species in grapes and wine (at trace levels) reported in the literature (Prendes et al. 2015, Trinidad et al. 2015, Tancinova et al. 2016).

\section{Minimizing the Risk of Mycotoxin Contamination along the Grape Chain}

Cropping system management. All factors involved in farming practice should be assessed prior to and during vineyard establishment. The main parameters affecting mycotoxin occurrence at preharvest stage are summarized in Figure 1. Choosing a suitable variety and its expected longevity are crucial to ensure high-quality products. However, an Argentinian study demonstrated that the age and variety of the vineyard and its predominant and total microbial population did not influence the presence of $A$. carbonarius (Barberis M et al. 2014).

Aspects such as training system and soil management must be taken into account to control all the microbial populations present in vineyards, including mycotoxigenic fungi. These contaminations can also be controlled by manipulating the host resistance or with the application of chemical or biological agents that act against pest and disease proliferation.

Trellising and training. Trellising should be considered when planting a vineyard to ensure the final quality of products. The trellis system should avoid sunburn or cluster crowd- ing during the growth period because too much vegetative growth can limit cluster development (Hocking et al. 2007, Somma et al. 2012). Trellising should also promote cluster aeration (Somma et al. 2012). A Uruguayan study investigating the effects of trellis system, planting density, and cordon height on the presence of Aspergillus spp. in vineyards showed that high densities and vegetative growth favored Aspergillus spp. presence (Ferrari et al. 2017).

The presence of Aspergillus spp. can be correlated with the positioning of the trellis. The incidences of $A$. carbonarius and ochratoxigenic strains of $A$. niger were higher with the parral system, while globally, $A$. niger prevailed in the high vertical shoot-positioned trellis (Chiotta et al. 2013). Since Aspergillus species are often found in the soil, the use of an espalier type system that places the canopy near the soil is associated with higher levels of OTA contamination (Somma et al. 2012).

Soil management. One of the prime parameters when choosing a proper cropping system is the type of soil. Vineyards can be planted in sandy, clay, or silty soils. The effect of these variables was not shown to be relevant to the incidence of Aspergillus section Nigri isolates; yet, combining clay soils, reduced tillage practices, and constant water availability can reduce A. carbonarius contamination (Hocking et al. 2007, Chiotta et al. 2013). Tillage and other practices that involve soil movement promote fungal contamination because the soil is the source of inoculums for the majority of fungi, and tillage can help them reach plant and fruits with negative effects, especially if tilling is performed during the ripening stage (Meyvaci et al. 2012).

Irrigation. Reduced tillage practices and the use of irrigation systems where the water availability is maintained, particularly in a furrow system instead of a drip system, can

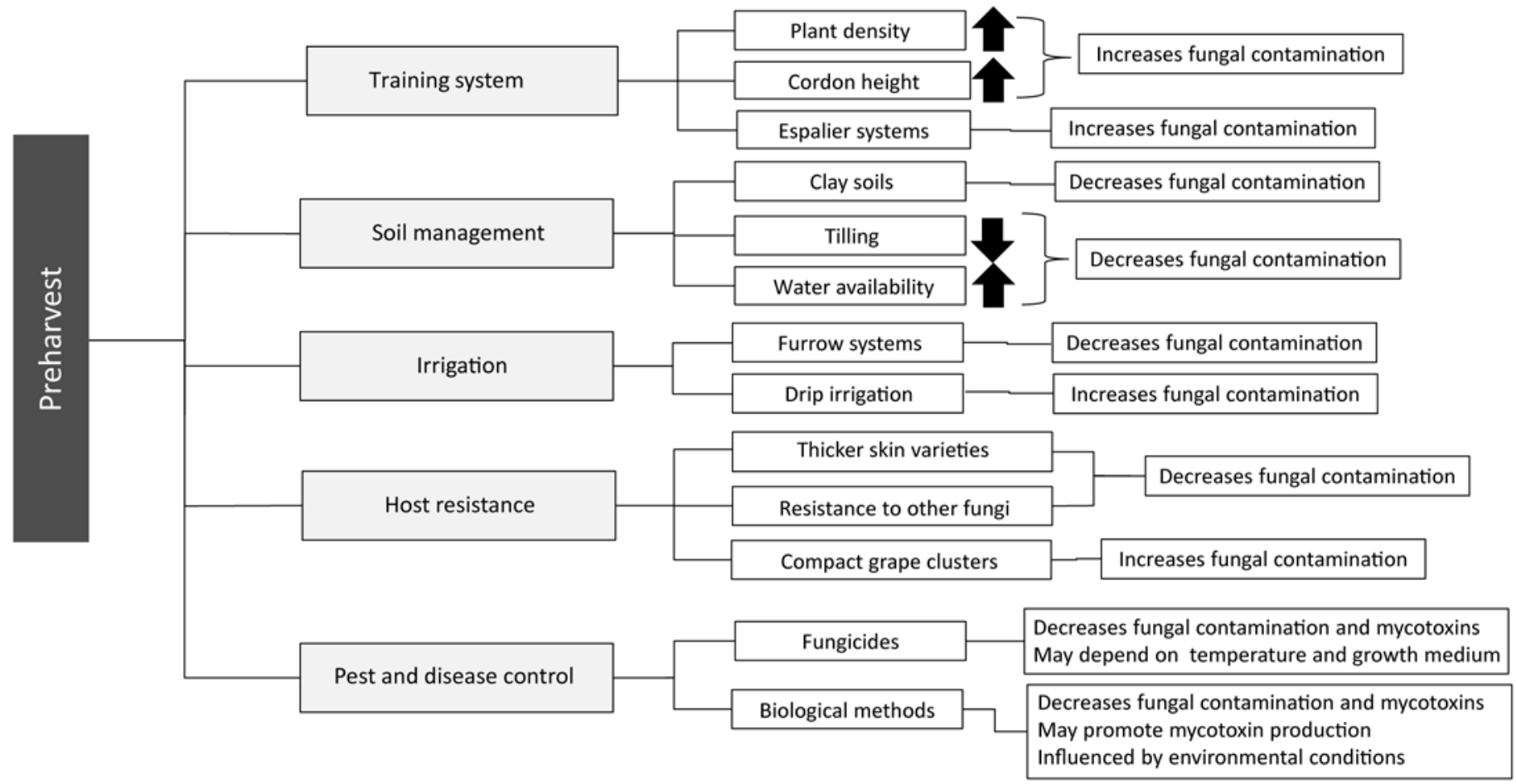

Figure 1 Parameters affecting mycotoxigenic fungi and their mycotoxins at the preharvest stage in the grape chain. 
minimize the incidence of Aspergillus species in grapes, including $A$. carbonarius and ochratoxigenic $A$. niger strains (Hocking et al. 2007, Chiotta et al. 2013). The preparation of the irrigation system, mainly in furrow systems, should be performed early to prevent soil dust from spreading fungi from the soil. This knowledge is in line with the results obtained in vineyards where incidence of $A$. carbonarius was associated with use of a drip irrigation system (Barberis $M$ et al. 2014).

Host resistance and defense. Resistance to downy mildew and Botrytis infection is a way of achieving protection against Aspergillus spp., since those pathogens can favor spreading of Aspergillus species (Hocking et al. 2007). The interactions between the different microbial populations have a strong effect on the spreading of a specific species by activating or inhibiting host defense mechanisms. Apaliya et al. (2017) found that by using trehalose pretreated Hanseniaspora uvarum, the defense mechanisms of table grapes could be stimulated in case of A. tubingensis infection. Similarly, Sporidiobolus pararoseus Y16 strain seemed to activate defense mechanisms against $A$. niger in grapes (Li et al. 2017). Ideally, grapevines should be resistant against pathogens and damaging meteorological events, such as intense rain, with thicker-skinned varieties presumably less susceptible to physical deterioration.

Pest and disease control. The presence of pests is a threat to the integrity of the fruit, and control of pests is a priority due to the substantial increase in fungal contamination as a result of grape surface damage. Infection of grapevines and consequent damage of grape skin by Lobesia botrana or Planococcus ficus is associated with greater fungal development (Chiotta et al. 2010, Cozzi et al. 2013). L. botrana triggers black Aspergilli infection and, consequently, OTA contamination by causing high sugar content in the exudates. Protection against this moth with insecticide and bio-insecticide (Bacillus thuringiensis and Beauveria bassiana formulations) was shown to prevent high levels of OTA in vineyards (Cozzi et al. 2009, 2013, Meyvaci et al. 2012).

Fungicide treatments are the main tool to control fungi in crops and need to be adjusted to the predicted risk of fungal contamination in vineyards. The combined use of two chemical compounds is advised in some cases in which risks are higher, and two sets of application may be necessary starting well before harvest (Somma et al. 2012). Cyprodinil, fludioxonil, tebuconazole, and trifloxystrobin are some of the main fungicides that have broad applications.

A study demonstrated that both Switch (Syngenta, Switzerland), a $37.5 \%$ cyprodinil and $25 \%$ fludioxonil fungicide, and Flint Max (Bayer, Germany), a fungicide with $500 \mathrm{~g} / \mathrm{kg}$ tebuconazole and $250 \mathrm{~g} / \mathrm{kg}$ trifloxystrobin, decreased $A$. carbonarius and $A$. ochraceus contamination and OTA production in grapes (Garcia-Cela et al. 2012). Even so, Tjamos et al. (2004) found that Chorus (Syngenta, Switzerland), a cyprodinil-based $(500 \mathrm{~g} / \mathrm{kg})$ fungicide, was ineffective for controlling Aspergillus species, contrary to data reported with Switch (registered to control Botrytis and Aspergillus spp. infection in grapes). These findings may indicate that the antifungal activity of
Switch is associated with the presence of fludioxonil. Cyprodinil, an anilinopyrimidine fungicide, has systemic properties and is absorbed from the cuticle waxy layers of the plant, while fludioxonil is a phenylpyrrole fungicide and exerts antifungal activity by contact when it is on the external surfaces of the commodity. Trifloxystrobin and tebuconazole affect respiration and sterol biosynthesis in membranes, respectively (Garcia-Cela et al. 2012).

The efficacy of the pyrimethanil-based fungicide Scala (Bayer, Germany) and the natural plant extract Stifénia (which consists of a homogenized fenugreek seed powder) as preharvest fungicides against $A$. carbonarius growth and OTA production was also reported in vines (Ahmed et al. 2015). Carbendazim, a benzimidazole antifungal agent, and difenoconazole, a triazole antifungal agent, have also been shown to inhibit growth of black Aspergilli species and OTA production in synthetic medium (Techarat et al. 2012). By contrast, Carbendazim was not proven to be effective against Aspergillus infection in Greek experiments of raisin vineyards (Tjamos et al. 2004).

Temperature is an important aspect to consider when assessing the efficacy of fungicides. A study with chlorothalonil, mancozeb, copper hydroxide, copper oxychloride, and tebuconazole-based commercial fungicides demonstrated that their in vitro activity against $A$. carbonarius growth and OTA accumulation was higher at the lowest temperature tested (15, over 20 , or $30^{\circ} \mathrm{C}$ ) (Terra et al. 2016). The same study also highlighted the differences between in vitro experiments (Czapek yeast extract agar and semisynthetic grape medium) and the effects on inoculated grapes, since the positive results of inhibition observed in vitro were not confirmed in grapes.

Fungal inhibition through competition with other microorganisms can occur at different stages of the grape production chain. In the field, the use of biocontrol approaches can complement chemical fungicides and overcome the increasing problems of fungicide resistance. Even though the presence of other species can cause competition for vital resources, assessing potential biocontrol agents (BCA) is important but can be complex. In fact, mycotoxin production can be stimulated during interactions between mycotoxigenic fungi and other species (Magan et al. 2010).

Table 2 lists some of the microorganisms found to have a potential role in control of mycotoxin-producing fungi in grapes. Yeasts are indicated as very adaptable to use as BCA because they can easily spread on the grape surface and compete effectively for nutrients (Sarrocco and Vannacci 2018).

Environmental conditions influence the contamination of grapes by spoilage fungi as well as the colonization of the BCA. A study showed that lower temperatures $\left(20\right.$ and $25^{\circ} \mathrm{C}$ versus $30^{\circ} \mathrm{C}$ ) and higher relative humidity (100 versus $\left.60 \%\right)$ favored colonization by the antagonists Metschnikowia pulcherrima and Aureobasidium pullulans and inhibition of $A$. carbonarius in grapes from day 2. OTA concentration was reduced at day 5 in all conditions tested (De Curtis et al. 2012).

Another study showed that 28 of 55 fungal isolates obtained from grape berries, namely A. pullulans, Cryptococcus magnus, and Candida sake strains, inhibited $A$. tubingensis 
infection in grapes, with A. pullulans showing the highest efficacy at $96 \%$ inhibition (Pantelides et al. 2015). Previously, Dimakopoulou et al. (2008) demonstrated the activity of 17 yeasts on A. carbonarius control and showed that A. pullulans was the most effective yeast in detached berry tests and in field conditions, with the latter experiment comparing the yeast to the application of a commercial fungicide (fludioxonil and cyprodinil based). The results of the field study with two different grape varieties showed reduction of OTA in the produced must and no significant difference between the commercial fungicide and the BCA for reducing $A$. carbonarius in the field.

Kluyveromyces thermotolerans (Lanchancea thermotolerans) strains have also been considered as BCA based on the observations that two strains reduced OTA production and growth rates of $A$. niger aggregate species and $A$. carbonarius in vitro, and OTA presence was reduced by $100 \%$ in the musts from contaminated Cabernet Sauvignon grapes (Ponsone et al. 2011). A more recent study has shown that the same species was a suitable BCA for Aspergillus section Nigri and OTA contaminations in grapes, with inhibitions of 27 to $100 \%$ in greenhouse and field experiments, respectively (Ponsone et al. 2016).

Cubaiu et al. (2012) confirmed the ability of strains of Saccharomyces cerevisiae and Kloeckera apiculata to control development of $A$. carbonarius and A. ochraceus and OTA production in vitro and on grapes. The mechanism involved in the inhibition was the regulation of mycotoxin biosynthesis by a reduction of the transcriptional activity of the polyketide synthase genes involved in the process.

When studying the antagonistic ability of yeasts, Prendes et al. (2018) found that 14 strains of Metschnikowia (pulcherrima or spp.), Starmerella bacillaris, and H. uvarum were able to act against Alternaria alternata infection of winegrapes and, consequently, tenuazonic acid production. As mentioned before, $H$. uvarum also reduced $A$. tubingensis infection by activating grape defense mechanisms (Apaliya et al. 2017).
In vitro experiments that assessed the ability to inhibit OTA production induced by $A$. carbonarius in 30 strains showed that nontoxic strains of A. section Nigri, Trichoderma spp., Cladosporium spp., Acremonium spp., Geotrichum spp., and one strain of A. flavus reduced OTA concentration by 40 to $100 \%$ (Barberis $\mathrm{C}$ et al. 2014).

Harvest management. During the collection of mature grapes and because of their thinner skin at this stage, the control of the harvest process is essential to avoid damage that favors the entrance of fungi in the fruit and leads to mycotoxin contamination (Hocking et al. 2007, Amezqueta et al. 2012).

The period in which harvest occurs should be controlled to reduce the time window until the initial processing step, which depends on the final product (e.g., table grapes, dried vine fruits, juice, or wine). Processing should occur as fast as possible, and proper sanitation procedures need to be adopted to ensure the quality of the product required for the next steps (Hocking et al. 2007).

Storage management. The essential parameters to control pathogens during storage of grapes include temperature and water activity, which must be below $5^{\circ} \mathrm{C}$ and 0.8 , respectively (Amezqueta et al. 2012). Grapes can be stored for shorter or longer periods before any of the processing steps, so it is mandatory to have proper control in this stage. Grapes are often stored using plastic materials to cover the boxes; however, the choice of material used may affect fungal contamination. A study on seedless grapes showed that the use of polyamide bags instead of the more common high-density polyethylene ones could reduce $A$. niger contamination (Camargo et al. 2012).

For table grapes, a storage temperature of $0^{\circ} \mathrm{C}$ combined with exposure to sulfur dioxide seems appropriate to control black Aspergilli species for a period of up to one month (Guzev et al. 2008). The application of modified atmosphere and the use of bioactive packages may provide additional protection for table grapes. Coatings with chitosan and two different Mentha essential oils (Mentha piperita L. or Mentha villosa Huds) led

Table 2 Biocontrol microorganisms with inhibitory potential on mycotoxin-producing fungi.

\begin{tabular}{|c|c|c|c|}
\hline Biocontrol microorganism & Target fungal species & Type of assay & Reference \\
\hline Aureobasidium pullulans & Aspergillus carbonarius & Grapes and field & (Dimakopoulou et al. 2008) \\
\hline $\begin{array}{l}\text { A. pullulans, Candida sake, and } \\
\text { Cryptococcus magnus }\end{array}$ & Aspergillus tubingensis & Grapes & (Pantelides et al. 2015) \\
\hline $\begin{array}{l}\text { Candida zemplinina M3, Metschnikowia aff. fructicola } \\
\text { M179, Pichia kluyveri M117, Saccharomyces cerevisiae } \\
\text { C297, and Saccharomyces cerevisiae M114 }\end{array}$ & $\begin{array}{l}\text { A. carbonarius and } \\
\text { Aspergillus ochraceus }\end{array}$ & In vitro, grapes & (Zhu et al. 2015) \\
\hline Hanseniaspora uvarum & A. tubingensis & Grapes & (Apaliya et al. 2017) \\
\hline $\begin{array}{l}\text { H. uvarum, Metschnikowia (pulcherrima or spp.), and } \\
\text { Starmerella bacillaris }\end{array}$ & Alternaria alternata & Grapes & (Prendes et al. 2018) \\
\hline Kloeckera apiculata and Saccharomyces cerevisiae & $\begin{array}{l}\text { A. carbonarius and } \\
\text { A. ochraceus }\end{array}$ & In vitro, grapes & (Cubaiu et al. 2012) \\
\hline \multirow[t]{2}{*}{$\begin{array}{l}\text { Kluyveromyces thermotolerans } \\
\text { (Lanchancea thermotolerans) }\end{array}$} & $\begin{array}{l}\text { Aspergillus niger aggregate } \\
\text { and } A \text {. carbonarius }\end{array}$ & In vitro & (Ponsone et al. 2011) \\
\hline & Aspergillus section Nigri & Greenhouse and field & (Ponsone et al. 2016) \\
\hline Penicillium adametzoides & A. carbonarius & In vitro & (Ahmed et al. 2015) \\
\hline
\end{tabular}


to a reduction in growth of $A$. niger, $B$. cinerea, $P$. expansum, and Rhizopus stolonifer, showing its potential application for control of fungal contamination (Guerra et al. 2016).

In wine production, the storage of grapes is of particular relevance to guarantee the safety of the final product and its required sensorial qualities. Ozone fumigation is a method with potential application for this purpose since it reduced fungal (including yeast) contamination by $50 \%$ and does not have negative effects on the levels of polyphenols and carotenoids if performed before the grape dehydration step that is sometimes used in winemaking (Botondi et al. 2015).

Biological approaches can also be adopted at this stage. Studying the effect of Bacillus subtilis, Trichoderma harzianum, and Trichoderma viride under storage conditions, Senthil et al. (2011) showed reductions in incidence of disease caused by spoilage fungi both in vitro and in vivo.

Application of natural compounds. Applying natural compounds to control fungal development is an approach with growing interest due to the increasing rejection of synthetic fungicides by consumers. This application can be done at different stages, with many studies focusing on applications to control spoilage in harvested grapes during storage as well as some successful in vitro studies performed at preharvest stages. Table 3 presents results on effective natural compounds, indicating the fungal species inhibited and the type of assay conducted.

Much interest has been expressed on the potential use of essential oils (EOs) as antifungal agents. Research in this field is diverse, with a wide range of EOs already tested against different microorganisms. EOs from lemon (Citrus lemon L.), eucalyptus (Eucalyptus globulus LABILL.), thyme (Thymus vulgaris), oregano (Origanum vulgare L.), sage (Salvia officinalis L.), and lavender (Lavandula angustifolia MILLER.) were used to inhibit $A$. niger and $A$. tubingensis, with greater fungal inhibition observed with $O$. vulgare L. and T. vulgaris L., followed by L. angustifolia MILLER. and S. officinalis L. (which only caused slower growth), and no inhibition demonstrated with C. lemon L. and E. globulus LABILL. EOs (Cisarova et al. 2016).

Sonker et al. (2014) tested 15 EOs for their in vitro efficacy in reducing growth of A. flavus, A. niger, and A. ochraceus. EOs obtained from Ageratum conyzoides Linn., Ocimum canum Sims, Piper methysticum Frost., Putranjiva roxburghii Wall, and Cymbopogon citratus (DC.) Stapf were the most

\begin{tabular}{|c|c|c|c|}
\hline Natural compound & Target fungal species & Type of assay & Reference \\
\hline \multicolumn{4}{|l|}{ Essential oils } \\
\hline $\begin{array}{l}\text { Ageratum conyzoides, Cymbopogon citratus, } \\
\text { Ocimum canum, Piper methysticum, } \\
\text { and Putranjiva roxburghii }\end{array}$ & $\begin{array}{l}\text { Aspergillus flavus, Aspergillus } \\
\text { niger and Aspergillus ochraceus }\end{array}$ & In vitro & (Sonker et al. 2014) \\
\hline Artemisia nilagirica & $\begin{array}{l}\text { A. flavus, } A \text {. niger and } \\
\text { A. ochraceus }\end{array}$ & In vitro and on grapes & (Sonker et al. 2015) \\
\hline $\begin{array}{l}\text { Blumea membranacea, Hyptis suaveolens, } \\
\text { and Ocimum gratissimum }\end{array}$ & $\begin{array}{l}\text { A. flavus, } A \text {. niger and } \\
\text { A. ochraceus }\end{array}$ & In vitro & (Sonker et al. 2015) \\
\hline $\begin{array}{l}\text { Cinnamomum cassia, Citrus reticulata, } \\
\text { C. citratus, and Eugenia caryophyllus }\end{array}$ & Aspergillus carbonarius & In vitro & (Lappa et al. 2017) \\
\hline $\begin{array}{l}\text { Cinnamomum verum, Eruca sativa, } \\
\text { Origanum vulgare, and Thymus vulgaris }\end{array}$ & A. carbonarius & $\begin{array}{l}\text { In vitro (synthetic } \\
\text { grape medium) }\end{array}$ & (El Khour et al. 2016) \\
\hline C. citratus & A. flavus, $A$. niger and $A$. ochraceus & In vitro and on grapes & (Sonker et al. 2014) \\
\hline $\begin{array}{l}\text { Lavandula angustifolia MILLER., Origanum vulgare } \\
\text { L., Salvia officinalis L., and Thymus vulgaris L. }\end{array}$ & A. niger and Aspergillus tubingensis & In vitro & (Cisarova et al. 2016) \\
\hline Ocimum basilicum & A. flavus & In vitro and on grapes & (Kumar et al. 2011) \\
\hline \multicolumn{4}{|l|}{ Others } \\
\hline Carvacrol encapsulated with Halloysite nanotubes & $\begin{array}{l}\text { Alternaria alternata, Botrytis cinerea, } \\
\text { Penicillium digitatum, Penicillium } \\
\text { expansum, and } A \text {. niger }\end{array}$ & In vitro and on grapes & (Shemesh et al. 2016) \\
\hline Chitosan & Fusarium oxysporum & In vitro and on grapes & (Irkin and Guldas 2014) \\
\hline Chitosan & $\begin{array}{l}\text { Penicillium chrysogenum and } \\
\text { Aspergillus parasiticus }\end{array}$ & In vitro & (Irkin and Guldas 2014) \\
\hline Chitosan and $O$. vulgare L. essential oil & Rhizopus stolonifer and $A$. niger & In vitro and on grapes & $\begin{array}{l}\text { (dos Santos et al. } \\
2012 \text { ) }\end{array}$ \\
\hline Garlic juice & $\begin{array}{l}\text { Penicillium citrinum, } P \text {. expansum, } \\
\text { Penicillium puberulum and } \\
\text { Penicillium verrucosum }\end{array}$ & In vitro & $\begin{array}{l}\text { (El-Samawaty et al. } \\
\text { 2013) }\end{array}$ \\
\hline Isothiocyanates & $P$. expansum and $A$. parasiticus & In vitro & (Manyes et al. 2015) \\
\hline Lecanicillium muscarium enzymes & A. carbonarius & Grapes & (Barghini et al. 2013) \\
\hline Metabolites of Bacillus amyloliquefaciens & A. niger & In vitro & (Raut et al. 2014) \\
\hline Natamycin & A. carbonarius & $\begin{array}{l}\text { In vitro (synthetic } \\
\text { grape-juice medium) }\end{array}$ & (Kogkaki et al. 2016) \\
\hline Pine resin & A. carbonarius & $\begin{array}{l}\text { In vitro (synthetic } \\
\text { grape-juice medium) }\end{array}$ & (Kogkaki et al. 2016) \\
\hline
\end{tabular}


promising ones, with inhibitions greater than 54\% for the three fungal isolates and Cymbopogon citratus (DC.) Stapf causing an inhibition of $100 \%$. The essential oil of $C$. citratus also inhibited production of aflatoxin B1 (AFB1) and OTA.

After testing 20 different EOs, Sonker et al. (2015) found that the Indian wormwood (Artemisia nilagirica [Clarke] Pamp.) EO was the most effective in vitro, inhibiting production of AFB1 and OTA and fungi contamination (including reduction of $A$. flavus, A. niger, and A. ochraceus by $100 \%$ ) on grapes. This EO showed fungistatic and fungicidal activities at $0.29 \mu \mathrm{L} / \mathrm{mL}$ and $0.58 \mu \mathrm{L} / \mathrm{mL}$, respectively. Moreover, the EOs from Blumea membranacea DC., Hyptis suaveolens (L.) Poit., and Ocimum gratissimum Linn inhibited the three fungal species by more than $46 \%$.

Addition of $1 \mu \mathrm{L} / \mathrm{mL}$ basil (Ocimum basilicum) EO to 1 $\mathrm{kg}$ of $V$. vinifera grapes stored in plastic containers resulted in a $62.5 \%$ reduction of $A$. flavus. The basil EO also showed a minimum inhibitory concentration of $1 \mu \mathrm{L} / \mathrm{mL}$ and inhibition of AFB1 production at $0.5 \mu \mathrm{L} / \mathrm{mL}$ (Kumar et al. 2011).

Several authors have studied the mode of action of essential oils in the inhibition of mycotoxin biosynthesis. A reduction in the expression of AcOTAnrps gene in A. carbonarius was observed when using EOs from E. caryophyllus, C. citratus, $C$. cassia, and $C$. reticulate, which is in line with previous studies that showed downregulation of acOTApks, acOTAnrps, acpks, laeA, and vea genes (which are involved in OTA biosynthesis) in the presence of EOs from $R$. officinalis, P. anisum, $C$. nobile, F. vulgare, E. cardamomum, and A. graveolens (El Khour et al. 2016, Lappa et al. 2017).

Based on the inhibition results obtained in vitro from $A$. alternata, B. cinerea, Penicillium digitatum, P. expansum, and $A$. niger, Shemesh et al. (2016) tested a packaging material for grapes constituted of polyamide films incorporating volatile carvacrol molecules encapsulated with Halloysite nanotubes and showed that 2 and $4 \%$ of carvacrol led to 25 and $27 \%$ reduction in grape decay, respectively.

After demonstrating the inhibitory potential of chitosan and O. vulgare L. EO in vitro, dos Santos et al. (2012) studied their application as a coating for grapes. The use of coating solutions of chitosan at $5 \mathrm{mg} / \mathrm{mL}$ and $\mathrm{EO}$ at $2.5 \mu \mathrm{L} / \mathrm{mL}$ resulted in no development of Rhizopus stolonifer for $24 \mathrm{hr}$ at $12^{\circ} \mathrm{C}$. However, infection of grapes by $A$. niger occurred in $33 \%$ of grapes after 12 days, and infection by $R$. stolonifer and $A$. niger reached 25 and $35 \%$ of fruits, respectively (at $25^{\circ} \mathrm{C}$ ).

Antifungal potential of natamycin and pine resin was confirmed on synthetic grape juice medium. Reduced growth and inhibition of OTA production was observed for three isolates of $A$. carbonarius (a complete inhibition was achieved with pine resin). The authors concluded that these effects were correlated with environmental conditions, namely temperature and $\mathrm{a}_{\mathrm{w}}$ (Kogkaki et al. 2016).

Microbial metabolites have also been tested. Lecanicillium muscarium cell-wall degrading enzymes, which include mainly chitinases, reduced $A$. carbonarius contamination in white and red grapes by 95 and $89 \%$, respectively (Barghini et al. 2013). Bacillus amyloliquefaciens 1014 was shown to produce metabolites that can highly inhibit $A$. niger growth. The thermal stability of these compounds showed that they could be applied in sterilized products and preserve their properties during this treatment (Raut et al. 2014). Finally, the application of isothiocyanates showed that after 20 days, P. expansum and $A$. parasiticus were inhibited in solid medium by concentrations of isothiocyanates greater than 50 and $5 \mathrm{mg}$, respectively (Manyes et al. 2015).

Processing management. Handling and processing of grapes will be further discussed based on the final grape product: table grapes, grape juice, dried vine fruits, and wine (including special wines). For each grape product, a simplified flow chart is presented (Figure 2), and relevant studies on strategies to reduce contaminations are reviewed.

Reduction of mycotoxins in the final products can be achieved by applying different methods, including biological and physical ones. The occurrence of OTA in grape products is the main focus; however, the presence of AF and PAT is also mentioned. AF are of concern in dried vine fruits because of the development of $A$. flavus strains during drying. Penicillium spp., particularly P. expansum, are known to contaminate apples and pears, produce PAT, and (although less frequently) can contaminate grapes, with PAT detected in grapes, grape juice, and occasionally, wine (Diaz et al. 2011). In the grape chain, $P$. expansum can contaminate stored table grapes. In grapes for wine, the fungus has been isolated from apparently healthy grapes, and PAT may be detected in grape must but rarely in wine because it is degraded by yeast during fermentation (Scott et al. 1977).

Table grapes. For table grapes, which do not undergo further processing steps, identifying grapes suffering from discoloration can minimize risk for OTA contamination since this is a typical alteration that results from black Aspergilli infection (Hocking et al. 2007). Besides the strategies mentioned for storage (as the application of natural compounds or of fumigants), dipping grapes into an alkaline solution may reduce OTA levels by degradation, as discussed in Serratosa et al. (2010). The use of radiation to reduce spoilage of table grapes can be effective and, when used in combination with $\mathrm{SO}_{2}$, can assure an appropriate storage until consumption. However, the maintenance of organoleptic and nutritional properties needs to be assured when applying radiation (Barkai-Golan and Follett 2017).

The inoculation of table grapes with B. subtilis liquid culture or its supernatant, but not with its volatile compounds, inhibited $A$. carbonarius growth, confirming previous results on its in vitro efficacy and identifying a possible application during storage (Jiang et al. 2014b). S. pararoseus Y16 strain has also been studied for its possible application during storage of table grapes against $A$. niger. S. pararoseus Y16 reduced infection and induced resistance in the fruits. A proper proliferation of S. pararoseus Y16 was observed without affecting the properties of the grapes (Li et al. 2017).

Grape juice. The interest in fruit juices for their nutritional value makes it relevant to assess these products for contamination risks. Together with wine, grape juices are the second most frequent source of OTA intake following grain products (Mandappa et al. 2018). Besides OTA, Alternaria 
toxins were already detected in grape juices (Asam et al. 2012, Liu and Rychlik 2015), and the presence of PAT is a cause of concern.

Dachery et al. (2017) studied the effect of grape processing steps on OTA during grape juice production and winemaking and found 73,66 , and $44 \%$ reductions in OTA level for grape juice, red wine, and white wine, respectively.
In grape juice, which does not undergo fermentation, yeast biocontrol strategies involve the application of microorganisms with low or no fermentative activity. Fiori et al. (2014) reported that two low-fermenting strains (Candida intermedia and $L$. thermotolerans) were more effective than two non-fermenting ones (Cyberlindnera jadinii and Candida friedrichii) for controlling development of $A$. carbonarius and reducing
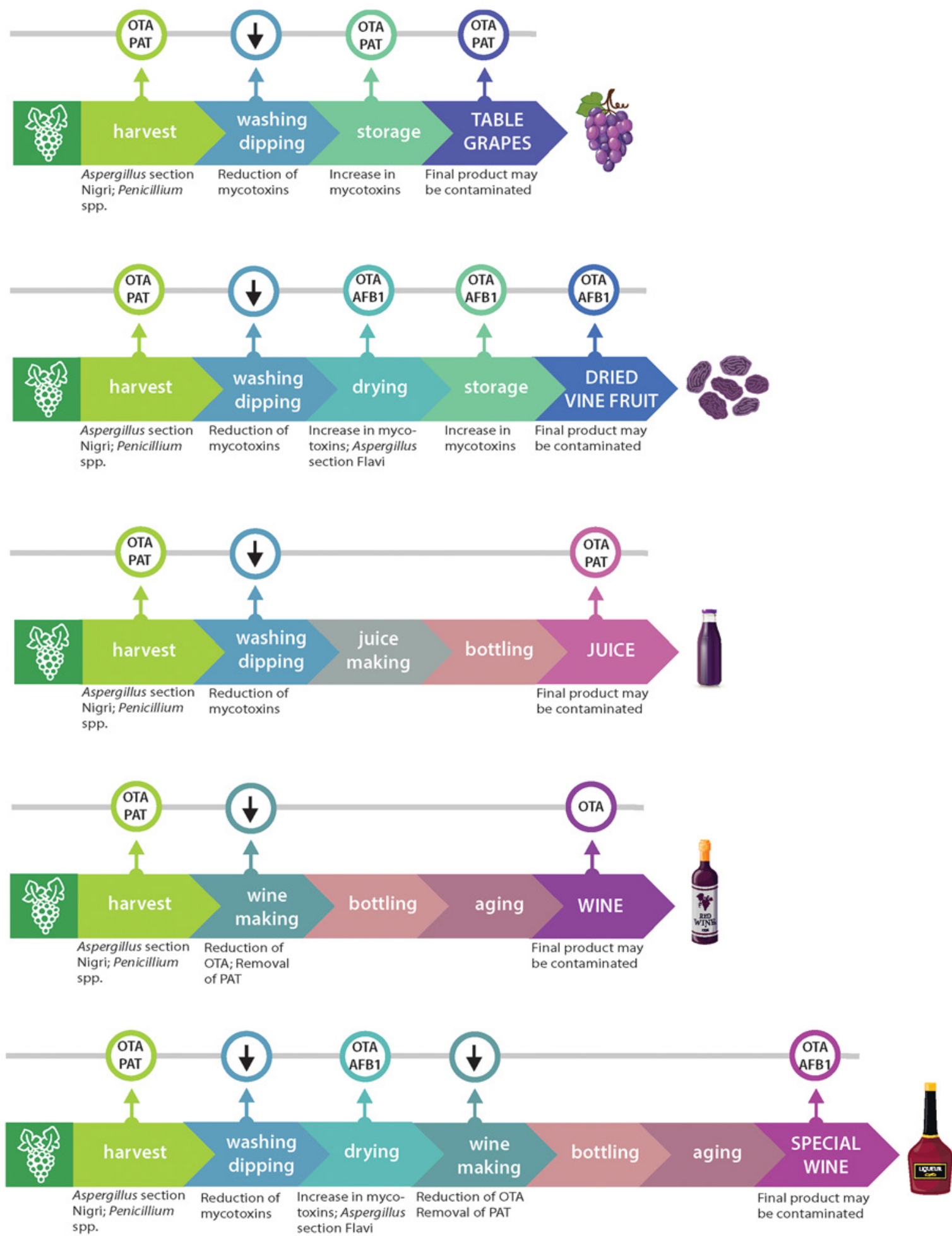

Figure 2 Simplified flowcharts for the main grape products: table grapes, dried vine fruits, grape juice, wine, and special wines (usually with ethanol content above 15\%). OTA, ochratoxin A; PAT, patulin; AFB1, aflatoxin B1. 
OTA levels in grape juice, indicating that reduction of OTA possibly resulted from adsorption activity. In another study that included 21 different strains isolated from grapes, Candida famata 17, Kloeckera sp. B2, Cryptococcus laurentii B4, Candida guilliermondii S1, and three strains of Candida lusitaniae were most effective for inhibiting OTA production by $A$. carbonarius in both yeast extract sucrose medium and grape juice (Var et al. 2011).

Farbo et al. (2016) tested a prototype packed bed bioreactor with yeast cells (C. intermedia) immobilized in alginate beads and reported the immobilization did not prevent adsorption of OTA in grape juice. OTA levels decreased by more than $80 \%$ within $48 \mathrm{hr}$ of treatment. Nevertheless, adsorption of OTA on yeast cell walls is a reversible physical-chemical phenomenon in which equilibrium is established between bound and free toxin (Petruzzi et al. 2015).

Treatments with ozone in fruit juices can be used to provide the required safety of these products and reduce levels of mycotoxins, as was reported by Cataldo et al (2008) and Asokapandian et al. (2018) for PAT content in apple juice. Gamma irradiation has also been considered to control mycotoxin contamination, and a treatment of $30.5 \mathrm{kGy}$ was found to reduce OTA levels in grape juice and wine by approximately 20\% (Calado et al. 2018).

Dried vine fruits. Dried vine fruits include raisins (naturally dried grapes), sultanas (dried grapes pretreated with a drying emulsion, which results in a light color and a slightly sweeter flavor compared with raisins), and currants (dried black seedless grapes). In the production of dried vine fruits, presence of mycotoxins depends on the initial content in grapes, the concentration effect due to drying, and further toxin production during drying and storage if temperature and water activity conditions favor mycotoxin production (Covarelli et al. 2012). Depending on edaphoclimatic conditions, OTA content in these products is usually higher than in other grape products. OTA accumulation in dried vine fruits starts before harvest (during berry maturation) and continues during drying while conducive water activity conditions persist, yielding dried vine fruits with higher OTA levels. The occurrence of AFs in dried vine fruits is also of concern, with AFB1 detected in several studies (Juan et al. 2008, Azaiez et al. 2015, Jeszka-Skowron et al. 2017).

Prior to drying, grapes may undergo a pretreatment with an alkaline solution to clean the surface and increase the permeability of the skin, allowing for a faster drying stage. Several studies were developed to compare dipping and drying conditions (Serratosa et al. 2010, Sen et al. 2016). Natural drying under the sun without additional treatment increases the risk of black Aspergillus development and OTA contamination. Dipping grapes in an alkaline solution before drying reduces the risk of contamination, and use of a controlled drying chamber further minimizes this risk. Serratosa et al. (2010) showed that using a drying chamber at $50^{\circ} \mathrm{C}$ with a relative humidity of $20 \%$ prevented fungal growth and OTA accumulation. In addition, the study found that the increase in OTA content was lower than expected, taking into account the concentration factor due to drying. The latter finding implies a degradation of OTA possibly caused by the dipping solution.

A survey in southern Spain that studied changes in the mycoflora of grapes during dehydration (Valero et al. 2005) showed an increase in the incidence of Aspergillus spp. in grapes over time with a predominance of black Aspergillus species, while the water activity in drying grapes decreased from about 0.95 to 0.75 . These conditions, associated with high temperatures and the germicidal effect of ultraviolet rays, favor growth of xerotolerant Aspergillus section Nigri strains over other species.

Mitigation tools are used to reduce fungal load, reduce mycotoxin accumulation, or even destroy mycotoxins. One of these approaches is the use of gamma radiation. Inactivation of fungal spores due to irradiation is achievable (Kanapitsas et al. 2015, Kanapitsas et al. 2016), with consequent reduction in the accumulation of AFB1 and OTA. However, the ability of irradiation to destroy mycotoxins is controversial and dependent on their location in the berry (superficial or internal) and on water content (Calado et al. 2014). In grapes used for raisins, Kanapitsas et al. (2015) found reductions in AFB1 levels of 29 and $65 \%$ in naturally contaminated samples and $A$. parasiticus-spiked raisins, respectively. The reduction in OTA was approximately $88 \%$ in naturally contaminated samples, and OTA was not detected in A. carbonarius-spiked samples (Kanapitsas et al. 2016).

The application of electron beam treatment ( $\beta$-radiation) to decrease spore contamination (genera Aspergillus, Byssochlamys, Eurotium, and Penicillium) in raisins was also tested, resulting in reductions of more than $1 \log$ when applying a dosage of more than $31.8 \mathrm{kGy}$ (Etter et al. 2018). However, this is a much larger radiation dose than that currently regulated in the European Union.

Wine. Levels of OTA carried over from grapes to wines will depend on the initial level in the grapes as well as on the technology of winemaking (Figure 3). Of the main steps included in vinification, the use of biological agents has great

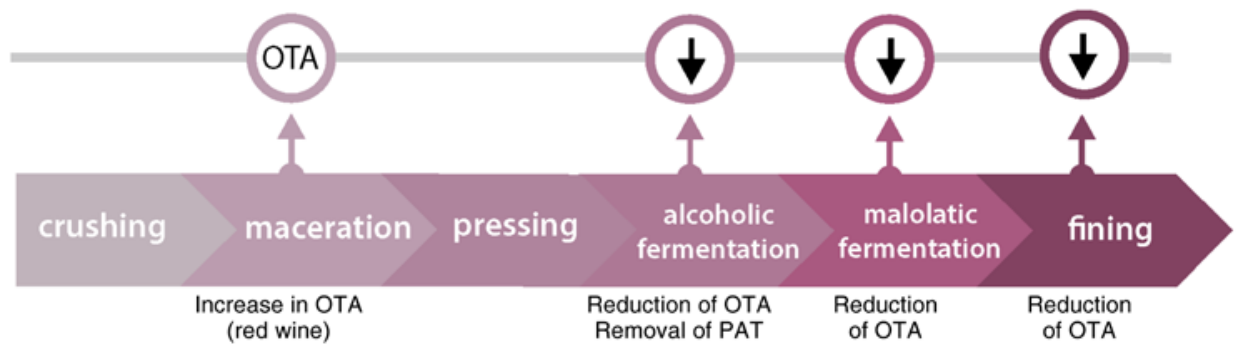

Figure 3 Simplified flowchart for the main winemaking steps. OTA, ochratoxin A; PAT, patulin. 
potential for reducing mycotoxin contamination in wine. Application can take place during fermentation, combining mycotoxin binding and fermentation, or at other stages with the addition of nonviable cells (Hocking et al. 2007).

Using the concept of the Food Safety Objective (Pitt et al. 2013), most of the steps involved in winemaking contribute to a decrease in OTA content. The final carryover of OTA is the result of the combination of all stages in the wine chain. Due to these, Dachery et al. (2017) observed a reduction in OTA contamination of 66 and $44 \%$ for red and white wine, respectively.

Sweet, dessert, or fortified wines tend to have a higher level of OTA due to its higher level in grapes, while red wines tend to have a higher level than rosé or white wines primarily because of the initial steps of the winemaking process (Covarelli et al. 2012, Quintela et al. 2013). After crushing, winemaking starts with a maceration step involving the contact between must and grape skin to increase the extraction of phenolic compounds (and other compounds) from the grape skin. This maceration step is longer in red wines than in white wines; contact between grapes and must favors the solubility of OTA in musts (Quintela et al. 2013).

After crushing and maceration, pressing separates grape skins (pomace) from must. Gambuti et al. (2005) studied the effect of applied pressure at this step and found that increasing pressure increases the volume of must and the amount of OTA extraction from skins. Others observed a 4-fold increase in OTA in the must when pressing pressure increased 10-fold (Quintela et al. 2013).

OTA has a high affinity for pomace; therefore, the use of pomace to remove OTA from contaminated musts after pressing has been suggested (Solfrizzo et al. 2010). OTA also binds to other solids present in the fermenting must (e.g., yeast, small fragments of grape skins or seeds, and other suspended solids), and this physical-chemical adsorption process can be explored to remove OTA in clarification steps after alcoholic fermentation, malolactic fermentation, and fining.

Jiang et al. (2014a) studied the effect of $A$. carbonarius inoculum in grapes on winemaking. Different amounts of $A$. carbonarius spores were added to grapes after crushing, and their development and OTA accumulation were followed during winemaking. The presence of this inoculum did not significantly affect the winemaking process and yielded wines with similar properties. The number of $A$. carbonarius spores increased slightly in the first hours after inoculation but then decreased sharply and were detected at residual levels after 24 to $48 \mathrm{hr}$. OTA content increased after inoculation and tended to decrease continuously during winemaking; however, it was not clear if the fungus was producing OTA during the winemaking process. Most OTA was removed from wine with pressing, at which point very high levels of OTA in pomace were obtained.

The accumulation of OTA during winemaking is also inhibited by the alcohol content. A study showed that a concentration of ethanol greater than $2 \%(\mathrm{v} / \mathrm{v})$ was enough to significantly delay Aspergillus spp. growth and inhibit OTA production (Jiang et al. 2015).
Several authors studied the fate of OTA during alcoholic fermentation with different yeast species in synthetic medium, must, and wine. Binding strategies can be used to guarantee product safety by decreasing OTA content. Wine is particularly relevant in this situation because fermentation starter cultures can also have binding potential. Commercial strains of $S$. cerevisiae removed OTA by up to $68 \%$ in one study (Quintela et al. 2013). These authors observed that OTA removal was mainly due to adsorption, but the microbial degradation of OTA could not be excluded (Ciconova et al. 2010). Similarly, different strains of $S$. cerevisiae caused a 20 to $70 \%$ adsorption of OTA in grape must. However, because this is a reversible phenomenon, the stability of these bonds is weak and the contact of these yeasts with an OTAfree must releases more than $55 \%$ of the bonded toxin, which can be a challenge for practical application of this approach (Petruzzi et al. 2015). Selection of fermentative strains that simultaneously inhibit undesirable fungal incidences and consequent mycotoxin production during processing is promising. However, achieving inhibition during and after fermentation is a challenge considering the changes that occur during this process, mainly the increase in medium acidity (Cubaiu et al. 2012).

The evolution of OTA during alcoholic fermentation was also studied in a spiked must (Esti et al. 2012). OTA depletion started at the beginning of fermentation with a constant removal rate, and slightly greater removal was achieved in the presence of grape skins in the study. Two phases have been identified: an initial phase in which content of OTA varied due to adsorption/desorption from grape skins and where OTA content may increase if grape skins are contaminated, and a second phase in which the presence of yeast surpassed the effect of grape skins and adsorption governs OTA removal. OTA content found in lees, a solid fraction obtained after alcoholic fermentation that includes most of the yeast cells, is much higher than the concentration left in wine. After malolactic fermentation, a reduced effect on OTA content was observed that was mainly attributed to the ethanol content of wine as well as the lower amount of solids (Fernandes et al. 2007, Mateo et al. 2010).

Strategies to reduce mycotoxin levels through adsorption or degradation can rely on biological agents other than the mentioned fermentative strains. The application of antagonistic yeasts can promote OTA removal during winemaking. Patharajan et al. (2011) found that some yeasts may remove OTA, primarily by degradation. Among tested strains, $M$. pulcherrima MACH1 and Pichia guilliermondii M8 degraded up to $80 \%$ of OTA by an unknown mechanism. Malolactic fermenting bacteria can also be used to remove OTA. Pediococcus parvulus strains isolated from wines that underwent spontaneous malolactic fermentation were tested for OTA removal with promising in vitro results but were less efficient in natural grape musts (Abrunhosa et al. 2014).

Kapetanakou et al. (2012) studied the effect of several bacterial and yeast isolates on the inhibition of $A$. carbonarius growth in synthetic grape medium in different environmental conditions and observed that no inhibition occurred with the 
bacterial isolates (probably due to the $\mathrm{pH}$ 3) and that reductions in OTA, although observed in both cases, were more significant with yeasts (up to 65\%). In beverages (grape juice, red wine, and beer), the greater reduction in OTA was also observed with yeasts and was most likely caused by adsorption to cell walls (Kapetanakou et al. 2012). The best in vitro results were obtained with mixed cultures including Hanseniaspora guilliermondii, Issatchenkia occidentalis, Issatchenkia orientalis, Kluyveromyces dobzhankii, L. thermotolerans, Pichia fermentas, $P$. guilliermondii, and $S$. cerevisiae.

OTA adsorption to yeast cell walls has been attributed to the presence of mannoproteins and beta-glucans, and this is also explored in fining stages. Adsorption of OTA improved with autoclaved cells, possibly due to heat-induced changes in the surface properties of the cells (Piotrowska et al. 2013). The same behavior has been observed for bacterial cells, with adsorption of $B$. subtilis higher in autoclaved cells than in viable cells (Shi et al. 2014). This study also showed that a $B$. subtilis strain with inhibitory activity against $A$. ochraceus and $A$. carbonarius could adsorb OTA and that its cell-free supernatant degraded approximately $97 \%$ of the mycotoxin.

The degradation of mycotoxins by yeasts during fermentation has also been tested for AFB1. AFB1 concentration was found to decrease slightly and significantly in the fermentation of beer and grape must, respectively (Inoue et al. 2013). The decrease in beer was marginal and caused by adsorption, whereas a decrease of up to $30 \%$ was observed in wine and attributed to the production of a hydrated derivative of the toxin. Differences in degradation during beer and wine fermentation could be due to the use of different yeast strains and fermentation conditions (temperature and $\mathrm{pH}$ ).

Different enological fining agents are used at fining stages to aid wine clarification and remove several undesirable compounds. Many products are used at this stage, and most have been tested for OTA adsorption in other comprehensive reviews (Quintela et al. 2013). However, these products are not specific for OTA and remove other compounds responsible for the flavor, taste, and color of wines. For these reasons, the removal of OTA by these products should be regarded as a collateral effect and not as their main role in winemaking.

In wines with high ethanol content (Figure 2), the presence of OTA depends on its initial content in grapes and on the wine produced. Production of some special wines includes a grape-drying stage, and therefore these wines tend to have higher OTA content than table wines. This drying step can also affect the aromatic profile of the final product (Barata et al. 2012).

Bejarano et al. (2010) evaluated the effect of drying in musts and observed a much higher OTA content when grapes were dried naturally than when they were dried in a climatic chamber at $40^{\circ} \mathrm{C}$ and with a relative humidity of $10 \%(28.8$ $\mu \mathrm{g} / \mathrm{kg}$ versus $6.9 \mu \mathrm{g} / \mathrm{kg}$ ). However, a sensory analysis of grape musts revealed a slightly higher preference for the sun-dried grapes. The effect of maceration and fermentation on OTA was also reported for sweet winemaking. A progressive decrease in OTA content was observed during aging and was more accentuated when aging took place in oak barrels (up to $37 \%$ after 90 days) (Bejarano et al. 2010).

Wines with a high ethanol content produced from overripened and dried grapes are particularly susceptible to contamination with AFs as well. The co-occurrence of AFs and OTA was reported in special wines, with both toxins present in $20 \%$ of the samples $(\mathrm{n}=30)$ but at low levels $(\mathrm{OTA}<2 \mu \mathrm{g} / \mathrm{L}$ and AFs $<0.1 \mu \mathrm{g} / \mathrm{L}$ ) (Di Stefano et al. 2015).

\section{Conclusions}

The exposure of grapes to fungal contamination in the field can increase health risks due to the presence of mycotoxins. Although diverse fungal species can contaminate grapes, OTA-producing species, mainly black Aspergillus, are by far the greatest problem in grape spoilage. OTA is mainly a preharvest problem, but the toxin is resilient and present in many grape products. Occasionally, other fungi produce mycotoxins in grapes, such as PAT by P. expansum or AFs by Aspergillus section Flavi. The occurrence of PAT is mainly a preharvest problem in table grapes and grape juices but is rarely present at concerning levels. By contrast, AFs are mainly a postharvest problem in dried vine fruits and can also occur in special wines due to improper drying conditions. In the past decades, black Aspergillus spp. was also shown to produce FB2; however, the levels in grapes and in derived products (as wine) are not causes for concern.

Plant-pathogen interactions are complex, and with climate change, fungal development in grapes may change from the current situation in each region. This can allow for the proliferation of different species and the occurrence of other mycotoxins and challenge the safety of grapes and derived products. These aspects raise the need for new efforts at cropping and processing levels in addition to the current practices reviewed here. The diversity of conditions under which the different grape products are obtained may also lead to fungal proliferation and mycotoxin production. Therefore, the adoption of an integrated vision on the pre- and postharvest strategies is crucial to achieve an overall mitigation of risks.

\section{Literature Cited}

Abrunhosa L, Paterson R, Kozakiewicz Z, Lima N and Venâncio A. 2001. Mycotoxin production from fungi isolated from grapes. Lett Appl Microbiol 32:240-242.

Abrunhosa L, Calado T and Venâncio A. 2011. Incidence of fumonisin $\mathrm{B}(2)$ production by Aspergillus niger in Portuguese wine regions. J Agric Food Chem 59:7514-7518.

Abrunhosa L, Inês A, Rodrigues AI, Guimarães A, Pereira VL, Parpot P, Mandes-Faia A and Venâncio A. 2014. Biodegradation of ochratoxin A by Pediococcus parvulus isolated from Douro wines. Int J Food Microbiol 188:45-52.

Ahmed H, Strub C, Hilaire F and Schorr-Galindo S. 2015. First report: Penicillium adametzioides, a potential biocontrol agent for ochratoxinproducing fungus in grapes, resulting from natural product pre-harvest treatment. Food Control 51:23-30.

Amezqueta S, Schorr-Galindo S, Murillo-Arbizu M, Gonzalez-Penas E, Lopez de Cerain A and Guiraud JP. 2012. OTA-producing fung in foodstuffs: A review. Food Control 26:259-268.

Apaliya MT, Zhang H, Yang Q, Zheng X, Zhao L, Kwaw E and Mahunu GK. 2017. Hanseniaspora uvarum enhanced with trehalose induced 
defense-related enzyme activities and relative genes expression levels against Aspergillus tubingensis in table grapes. Postharvest Biol Tec 132:162-170.

Asam S, Lichtenegger M, Liu Y and Rychlik M. 2012. Content of the Alternaria mycotoxin tenuazonic acid in food commodities determined by a stable isotope dilution assay. Mycotoxin Res 28:9-15.

Asokapandian S, Periasamy S and Swamy GJ. 2018. Ozone for fruit juice preservation. In Fruit Juices. Rajauria G and Tiwari BK (eds.), pp. 511-527. Academic Press, San Diego.

Atoui A, Mitchell D, Mathieu F, Magan N and Lebrihi A. 2007. Partitioning of ochratoxin A in mycelium and conidia of Aspergillus carbonarius and the impact on toxin contamination of grapes and wine. J Appl Microbiol 103:961-968.

Azaiez I, Font G, Manes J and Fernandez-Franzon M. 2015. Survey of mycotoxins in dates and dried fruits from Tunisian and Spanish markets. Food Control 51:340-346.

Barata A, Malfeito-Ferreira M and Loureiro V. 2012. The microbial ecology of wine grape berries. Int J Food Microbiol 153:243-259.

Barberis CL, Pena G, Carranza C and Magnoli CE. 2014. Effect of indigenous mycobiota on ochratoxin A production by Aspergillus carbonarius isolated from soil: Ochratoxin in mixed cultures. Mycotoxin Res 30:1-8.

Barberis MG, Gaij Merlera G, Reynoso MM, Chulze SN and Torres AM. 2014. Factors affecting distribution and abundance of Aspergillus section Nigri in vineyard soils from grapevine growing regions of Argentina. J Sci Food Agric 94:3001-3007.

Barghini P, Esti M, Pasqualetti M, Silvi S, Aquilanti A and Fenice M. 2013. Inhibition of the ochratoxin-A producer Aspergillus carbonarius on white and red grapes by crude cell-wall degrading enzymes from the Antarctic fungus Lecanicillium muscarium CCFEE 5003. J Environ Prot Ecol 14:1673-1679.

Barkai-Golan R and Follett PA. 2017. Irradiation for quality improvement of individual fruits. In Irradiation for Quality Improvement, Microbial Safety and Phytosanitation of Fresh Produce. Barkai-Golan R and Follett PA (eds.), pp. 55-107. Academic Press, San Diego.

Battilani P and Camardo Leggieri M. 2015. OTA-grapes: A mechanistic model to predict ochratoxin A risk in grapes, a step beyond the systems approach. Toxins 7:3012-3029.

Battilani P, Logrieco A, Giorni P, Cozzi G, Bertuzzi T and Pietri A. 2004. Ochratoxin A production by Aspergillus carbonarius on some grape varieties grown in Italy. J Agric Food Chem 84:1736-1740.

Battilani P, Giorni P, Bertuzzi T, Formenti S and Pietri A. 2006. Black aspergilli and ochratoxin A in grapes in Italy. Int J Food Microbol 111:S53-S60

Bavaresco L, Vezzulli S, Battilani P, Giorni P, Pietri A and Bertuzzi T. 2003. Effect of ochratoxin A-producing Aspergilli on stilbenic phytoalexin synthesis in grapes. J Agric Food Chem 51:6151-6157.

Bejarano MJR, Dodero MCR and Barroso CG. 2010. Optimizing the process of making sweet wines to minimize the content of ochratoxin A. J Agric Food Chem 58:13006-13012.

Botondi R, De Sanctis F, Moscatelli N, Vettraino AM, Catelli C and Mencarelli F. 2015. Ozone fumigation for safety and quality of wine grapes in postharvest dehydration. Food Chem 188:641-647.

Calado T, Venâncio A and Abrunhosa L. 2014. Irradiation for mold and mycotoxin control: A review. Compr Rev Food Sci F 13:1049-1061.

Calado T, Fernandez-Cruz ML, Cabo Verde S, Venâncio A and Abrunhosa L. 2018. Gamma irradiation effects on ochratoxin A: Degradation, cytotoxicity and application in food. Food Chem 240:463-471.

Camardo Leggieri M, Battilani P, Mitchell D, Aldred D and Magan N. 2014. Hydro- and thermotimes for conidial germination kinetics of the ochratoxigenic species Aspergillus carbonarius in vitro, on grape skin and grape flesh. Fungal Biol 118:996-1003.
Camargo RB, Terao D, Peixoto AR, Ono EO, Cavalcanti LS and da Costa RM. 2012. Modified atmosphere in preserving the quality of 'Thompson Seedless' grapes and reducing Aspergillus rot. Summa Phytopathol 38:216-222.

Cataldo F. 2008. Ozone decomposition of patulin-A micotoxin and food contaminant. Ozone-Sci Eng 30:197-201.

Chiotta ML, Ponsone ML, Torres AM, Combina M and Chulze SN. 2010. Influence of Planococcus ficus on Aspergillus section Nigri and ochratoxin A incidence in vineyards from Argentina. Lett Appl Microbiol 51:212-218.

Chiotta ML, Ponsone ML, Sosa DM, Combina M and Chulze SN. 2013. Biodiversity of Aspergillus section Nigri populations in Argentinian vineyards and ochratoxin A contamination. Food Microbiol 36:182-190.

Ciconova P, Laciakova A and Mate D. 2010. Prevention of ochratoxin A contamination of food and ochratoxin A detoxification by microorganisms-A review. Czech J Food Sci 28:465-474.

Cisarova M, Tancinova D and Medo J. 2016. Antifungal activity of lemon, eucalyptus, thyme, oregano, sage and lavender essential oils against Aspergillus niger and Aspergillus tubingensis isolated from grapes. Potravinarstvo: Scientific Journal for Food Industry 10:83-88.

Covarelli L, Beccari G, Marini A and Tosi L. 2012. A review on the occurrence and control of ochratoxigenic fungal species and ochratoxin A in dehydrated grapes, non-fortified dessert wines and dried vine fruit in the Mediterranean area. Food Control 26:347-356.

Cozzi G, Haidukowski M, Perrone G, Visconti A and Logrieco A. 2009. Influence of Lobesia botrana field control on black Aspergilli rot and ochratoxin A contamination in grapes. J Food Protect 72:894-897.

Cozzi G, Somma S, Haidukowski M and Logrieco AF. 2013. Ochratoxin A management in vineyards by Lobesia botrana biocontrol. Toxins 5:49-59.

Cubaiu L, Abbas H, Dobson ADW, Budroni M and Migheli Q. 2012. A Saccharomyces cerevisiae wine strain inhibits growth and decreases ochratoxin A biosynthesis by Aspergillus carbonarius and Aspergillus ochraceus. Toxins 4:1468-1481.

Dachery B, Veras FF, Magro LD, Manfroi V and Welke JE. 2017. Exposure risk assessment to ochratoxin A through consumption of juice and wine considering the effect of steam extraction time and vinification stages. Food Chem Toxicol 109:237-244.

De Curtis F, de Felice DV, Ianiri G, De Cicco V and Castoria R. 2012. Environmental factors affect the activity of biocontrol agents against ochratoxigenic Aspergillus carbonarius on wine grape. Int J Food Microbol 159:17-24.

De Rossi P, Ricelli A, Reverberi M, Bello C, Fabbri AA, Fanelli C, De Rossi A, Corradini D and Nicoletti I. 2012. Grape variety related trans-resveratrol induction affects Aspergillus carbonarius growth and ochratoxin A biosynthesis. Int J Food Microbol 156:127-132.

Di Stefano V, Pitonzo R, Avellone G, Di Fiore A, Monte L and Ogorka AZT. 2015. Determination of aflatoxins and ochratoxins in Sicilian sweet wines by high-performance liquid chromatography with fluorometric detection and immunoaffinity cleanup. Food Anal Methods 8:569-577.

Diaz GA, Yanez L and Latorre BA. 2011. Low occurrence of patulinproducing strains of Penicillium in grapes and patulin degradation during winemaking in Chile. Am J Enol Vitic 62:542-546.

Dimakopoulou M, Tjamos SE, Antoniou PP, Pietri A, Battilani P, Avramidis N, Markakis EA and Tjamos EC. 2008. Phyllosphere grapevine yeast Aureobasidium pullulans reduces Aspergillus carbonarius (sour rot) incidence in wine-producing vineyards in Greece. Biol Control 46:158-165.

dos Santos NST, Aguiar AJAA, de Oliveira CEV, de Sales CV, Silva SM, da Silva RS, Stamford TCM, and de Souza EL. 2012. Efficacy of the application of a coating composed of chitosan and Origanum vulgare L. essential oil to control Rhizopus stolonifer and Aspergillus niger in grapes (Vitis labrusca L.). Food Microbiol 32:345-353. 
El Khour R, Atoui A, Verheecke C, Maroun R, El Khoury A and Mathieu F. 2016. Essential oils modulate gene expression and ochratoxin A production in Aspergillus carbonarius. Toxins 8:2072-6651.

El-Samawaty AE-RMA, Moslem MA, Yassin MA, Sayed SRM and El-Shikh MS. 2013. Control of grape blue molding Penicillia by $\mathrm{Al}$ lium sativum. J Pure Appl Microbiol 7:1047-1053.

Esti M, Benucci I, Liburdi K and Acciaro G. 2012. Monitoring of ochratoxin A fate during alcoholic fermentation of wine-must. Food Control 27:53-56.

Etter D, Rupp A, Prange A and Drissner D. 2018. Inactivation of mould spores in a model system and on raisins by low-energy electron beam. Food Control 92:357-361

European Commission. 2006. Commission Regulation (EC) No 1881/2006 of 19 December 2006 setting maximum levels for certain contaminants in foodstuffs. Official Journal of the European Union L 364:15-16.

Farbo MG, Urgeghe PP, Fiori S, Marceddu S, Jaoua S and Migheli Q. 2016. Adsorption of ochratoxin A from grape juice by yeast cells immobilised in calcium alginate beads. Int J Food Microbiol 217:29-34.

Felsociova S, Rybarik LU, Tancinova D, Maskova Z and Kacaniova M. 2015a. Microfungi and mycotoxins of grapes from eastern Slovak wine region. J Microbiol Biotechnol Food Sci 4:12-15.

Felsociova S, Rybarik LU, Tancinova D, Maskova Z and Kacaniova M. 2015b. Microfungi and mycotoxins of grapes from Tokaj wine region. J Microbiol Biotechnol Food Sci 4:16-18.

Fernandes A, Ratola N, Cerdeira A, Alves A and Venâncio A. 2007. Changes in ochratoxin A concentration during winemaking. Am J Enol Vitic 58:92-96.

Ferrari V, Dellacassa E, Coniberti A and Disegna E. 2017. Role of grapevine vegetative expression on Aspergillus spp. incidence and OTA accumulation in wines produced in a temperate humid climate. Food Addit Contam Part A Chem Anal Control Expo Risk Assess 34:299-306.

Fiori S, Urgeghe Pietro P, Razzu S, Hammami W, Jaoua S and Migheli Q. 2014. Biocontrol activity of four non- and low-fermenting yeast strains against Aspergillus carbonarius and their ability to remove ochratoxin A from grape juice. Int J Food Microbiol 189:45-50.

Flamini R, Zanzotto A, de Rosso M, Lucchetta G, Dalla Vedova A and Bavaresco L. 2016. Stilbene oligomer phytoalexins in grape as a response to Aspergillus carbonarius infection. Physiol Mol Plant Pathol 93:112-118.

Gambuti A, Strollo D, Genovese A, Ugliano M, Ritieni A and Moio L. 2005. Influence of enological practices on ochratoxin A concentration in wine. Am J Enol Vitic 56:155-162.

Garcia-Cela E, Ramos AJ, Sanchis V and Marin S. 2012. Ochratoxigenic moulds and effectiveness of grape field antifungals in a climatic change scenario. J Sci Food Agric 92:1455-1461.

Garcia-Cela E, Crespo-Sempere A, Ramos AJ, Sanchis V and Marin S. 2014. Ecophysiological characterization of Aspergillus carbonarius, Aspergillus tubingensis and Aspergillus niger isolated from grapes in Spanish vineyards. Int J Food Microbiol 173:89-98.

Garcia-Cela E, Crespo-Sempere A, Gil-Serna J, Porqueres A and Marin S. 2015. Fungal diversity, incidence and mycotoxin contamination in grapes from two agro-climatic Spanish regions with emphasis on Aspergillus species. J Sci Food Agric 95:1716-1729.

Guerra ICD, de Oliveira PDL, Santos MMF, Lúcio ASSC, Tavares JF, Barbosa-Filho JM, Madruga MS and de Souza EL. 2016. The effects of composite coatings containing chitosan and Mentha (piperita L. or $x$ villosa Huds) essential oil on postharvest mold occurrence and quality of table grape cv. Isabella. Innov Food Sci Emerg Technol $34: 112-121$

Guzev L, Danshin A, Zahavi T, Ovadia A and Lichter A. 2008. The effects of cold storage of table grapes, sulphur dioxide and ethanol on species of black Aspergillus producing ochratoxin A. Int J Food Sci Technol 43:1187-1194.

Hocking AD, Leong SL, Kazi BA, Emmett RW and Scott ES. 2007. Fungi and mycotoxins in vineyards and grape products. Int J Food Microbiol 119:84-88

Inoue T, Nagatomi Y, Uyama A and Mochizuki N. 2013. Degradation of aflatoxin B1 during the fermentation of alcoholic beverages. Toxins 5:1219-1229.

Irkin R and Guldas M. 2014. Chitosan coating of red table grapes and fresh-cut honey melons to inhibit Fusarium oxysporum growth. J Food Process Pres 38:1948-1956.

Jeszka-Skowron M, Zgola-Grzeskowiak A, Stanisz E and Waskiewicz A. 2017. Potential health benefits and quality of dried fruits: Goji fruits, cranberries and raisins. Food Chem 221:228-236.

Jiang C, Shi J and Zhu C. 2013. Fruit spoilage and ochratoxin A production by Aspergillus carbonarius in the berries of different grape cultivars. Food Control 30:93-100.

Jiang C, Shi J, Cheng Y and Liu Y. 2014a. Effect of Aspergillus carbonarius amounts on winemaking and ochratoxin A contamination. Food Control 40:85-92.

Jiang C, Shi J, Liu Y and Zhu C. 2014b. Inhibition of Aspergillus carbonarius and fungal contamination in table grapes using Bacillus subtilis. Food Control 35:41-48.

Jiang C, Shi J, Chen X and Liu Y. 2015. Effect of sulfur dioxide and ethanol concentration on fungal profile and ochratoxin A production by Aspergillus carbonarius during wine making. Food Control 47:656-663.

Juan C, Zinedine A, Moltó JC, Idrissi L and Mañes J. 2008. Aflatoxins levels in dried fruits and nuts from Rabat-Salé area, Morocco. Food Control 19:849-853

Kanapitsas A, Batrinou A, Aravantinos A and Markaki P. 2015. Effect of $\gamma$-radiation on the production of aflatoxin $\mathrm{B}_{1}$ by Aspergillus parasiticus in raisins (Vitis vinifera L.). Radiat Phys Chem 106:327-332.

Kanapitsas A, Markaki P, Batrinou A, Sflomos C and Aravantinos A. 2016. Gamma radiation inhibits the production of ochratoxin A by Aspergillus carbonarius. Development of a method for OTA determination in raisins. Food Biosci 15:42-48.

Kapetanakou AE, Kollias JN, Drosinos EH and Skandamis PN. 2012. Inhibition of $A$. carbonarius growth and reduction of ochratoxin $\mathrm{A}$ by bacteria and yeast composites of technological importance in culture media and beverages. Int J Food Microbiol 152:91-99.

Khalesi M and Khatib N. 2011. The effects of different ecophysiological factors on ochratoxin A production. Environ Toxicol Phar 32:113-121.

Kogkaki EA, Natskoulis PI and Panagou EZ. 2016. Modeling the effect of natamycin, pine-resin and environmental factors on the growth and OTA production by Aspergillus carbonarius using response surface methodology. Food Res Int 79:19-28.

Kumar A, Shukla R, Singh P, Prakash B and Dubey NK. 2011. Chemical composition of Ocimum basilicum L. essential oil and its efficacy as a preservative against fungal and aflatoxin contamination of dry fruits. Int J Food Sci Technol 46:1840-1846.

Lappa IK, Kizis D, Natskoulis PI and Panagou EZ. 2015. Comparative study of growth responses and screening of inter-specific OTA production kinetics by $A$. carbonarius isolated from grapes. Front Microbiol 6:502.

Lappa IK, Simini E, Nychas GJE and Panagou EZ. 2017. In vitro evaluation of essential oils against Aspergillus carbonarius isolates and their effects on ochratoxin A related gene expression in synthetic grape medium. Food Control 73:71-80.

Lasram S, Barketi A, Mliki A and Ghorbel A. 2012. Growth and ochratoxin A production by Aspergillus carbonarius at different $\mathrm{pHs}$ and grape maturation stages. Lett Appl Microbiol 54:418-424. 
Li Q et al. 2017. The biocontrol effect of Sporidiobolus pararoseus Y16 against postharvest diseases in table grapes caused by Aspergillus niger and the possible mechanisms involved. Biol Control 113:18-25.

Liu Y and Rychlik M. 2015. Biosynthesis of seven carbon-13 labeled Alternaria toxins including altertoxins, alternariol, and alternariol methyl ether, and their application to a multiple stable isotope dilution assay. Anal Bioanal Chem 407:1357-1369.

Logrieco A, Ferracane R, Cozzi G, Haidukowsky M, Susca A, Mule $\mathrm{G}$ and Ritieni A. 2011. Fumonisin B2 by Aspergillus niger in the grape - wine chain: An additional potential mycotoxicological risk. Ann Microbiol 61:1-3.

Lorenzini M and Zapparoli G. 2015. Occurrence and infection of Cladosporium, Fusarium, Epicoccum and Aureobasidium in withered rotten grapes during post-harvest dehydration. Antonie Van Leeuwenhoek 108:1171-1180.

Lucchetta G, Bazzo I, Cortivo Gianluca D, Stringher L, Bellotto D, Borgo $\mathrm{M}$ and Angelini E. 2010. Occurrence of black aspergilli and ochratoxin A on grapes in Italy. Toxins 2:840-855.

Magan N, Aldred D, Hope R and Mitchell D. 2010. Environmental factors and interactions with mycobiota of grain and grapes: Effects on growth, deoxynivalenol and ochratoxin production by Fusarium culmorum and Aspergillus carbonarius. Toxins 2:353-366.

Mandappa IM, Basavaraj K and Manonmani HK. 2018. Analysis of mycotoxins in fruit juices. In Fruit Juices. Rajauria G and Tiwari BK (eds.), pp. 763-777. Academic Press, San Diego.

Manyes L, Luciano FB, Manes J and Meca G. 2015. In vitro antifungal activity of allyl isothiocyanate (AITC) against Aspergillus parasiticus and Penicillium expansum and evaluation of the AITC estimated daily intake. Food Chem Toxicol 83:293-299.

Maskova Z, Tancinova D, Rybarik LU and Felsoeciova S. 2014. Colonization of grape berries by the genus Fusarium and toxigenity of the most common representatives. J Microbiol Biotechnol Food Sci 3:256-258.

Mateo EM, Medina Á, Mateo R and Jiménez M. 2010. Effect of ethanol on the ability of Oenococcus oeni to remove ochratoxin A in synthetic wine-like media. Food Control 21:935-941.

Meyvaci KB, Aksoy U, Altindisli A, Eltem R, Askun T and Taskin E. 2012. Effect of yearly conditions and management practices on ochratoxin A production in Sultana Seedless vineyards. Food Addit Contam Part A Chem Anal Control Expo Risk Assess 29:1157-1167.

Mikusova P, Ritieni A, Santini A, Juhasova G and Srobarova A. 2010. Contamination by moulds of grape berries in Slovakia. Food Addit Contam Part A Chem Anal Control Expo Risk Assess 27:738-747.

Mikusova P, Srobarova A, Sulyok M and Santini A. 2013. Fusarium fungi and associated metabolites presence on grapes from Slovakia. Mycotoxin Res 29:97-102.

Morales H, Paterson RRM, Venâncio A and Lima N. 2013. Interaction with Penicillium expansum enhances Botrytis cinerea growth in grape juice medium and prevents patulin accumulation in vitro. Lett Appl Microbiol 56:356-360.

Morales-Valle H, Silva LC, Paterson R, Venâncio A and Lima N. 2011. Effects of the origins of Botrytis cinerea on earthy aromas from grape broth media further inoculated with Penicillium expansum. Food Microbiol 28:1048-1053.

Pantelides IS, Christou O, Tsolakidou MD, Tsaltas D and Ioannou N. 2015. Isolation, identification and in vitro screening of grapevine yeasts for the control of black Aspergilli on grapes. Biol Control 88:46-53.

Paterson RRM and Lima N. 2010. How will climate change affect mycotoxins in food? Food Res Int 43:1902-1914.

Paterson RRM and Lima N. 2011. Further mycotoxin effects from climate change. Food Res Int 44:2555-2566.
Paterson RRM, Venâncio A and Lima N. 2007. Why do food and drink smell like earth? In Communicating Current Research and Educational Topics and Trends in Applied Microbiology. Méndez-Vilas A (ed.), pp. 120-128. Formatex, Badajoz, Spain.

Paterson RRM, Venâncio A, Lima N, Guilloux-Bénatier M and Rousseaux S. 2018. Predominant mycotoxins, mycotoxigenic fungi and climate change related to wine. Food Res Int 103:478-491.

Patharajan S, Reddy KRN, Karthikeyan V, Spadaro D, Lore A, Gullino ML and Garibaldi A. 2011. Potential of yeast antagonists on in vitro biodegradation of ochratoxin A. Food Control 22:290-296.

Petruzzi L, Corbo MR, Baiano A, Beneduce L, Sinigaglia M and Bevilacqua A. 2015. In vivo stability of the complex ochratoxin A Saccharomyces cerevisiae starter strains. Food Control 50:516-520.

Piotrowska M, Nowak A and Czyzowska A. 2013. Removal of ochratoxin A by wine Saccharomyces cerevisiae strains. Eur Food Res Technol 236:441-447.

Pitt JI, Taniwaki MH and Cole MB. 2013. Mycotoxin production in major crops as influenced by growing, harvesting, storage and processing, with emphasis on the achievement of food safety objectives. Food Control 32:205-215.

Ponsone ML, Chiotta ML, Combina M, Dalcero A and Chulze S. 2011. Biocontrol as a strategy to reduce the impact of ochratoxin A and Aspergillus section Nigri in grapes. Int J Food Microbiol 151:70-77.

Ponsone ML, Nally MC, Chiotta ML, Combina M, Koehl J and Chulze SN. 2016. Evaluation of the effectiveness of potential biocontrol yeasts against black sur rot and ochratoxin A occurring under greenhouse and field grape production conditions. Biol Control 103:78-85.

Prendes LP, Merin MG, Andreoni MA, Ramirez ML and Ambrosini VIM. 2015. Mycobiota and toxicogenic Alternaria spp. strains in Malbec wine grapes from DOC San Rafael, Mendoza, Argentina. Food Control 57:122-128.

Prendes LP, Merín MG, Fontana AR, Bottini RA, Ramirez ML and Ambrosini VIM. 2018. Isolation, identification and selection of antagonistic yeast against Alternaria alternata infection and tenuazonic acid production in wine grapes from Argentina. Int J Food Microbiol 266:14-20.

Quintela S, Villaran MC, Lopez de Armentia I and Elejalde E. 2013. Ochratoxin A removal in wine: A review. Food Control 30:439-445.

Raut I, Calin M, Lazaroaie MM, Roseanu A, Badea-Doni M, Oancea F and Jecu L. 2014. Inhibition of toxigenic Aspergillus niger by microbial metabolites. Rev Chim 65:779-783.

Rousseaux S, Diguta CF, Radoi-Matei F, Alexandre H and GuillouxBenatier M. 2014. Non-Botrytis grape-rotting fungi responsible for earthy and moldy off-flavors and mycotoxins. Food Microbiol $38: 104-121$

Sarrocco S and Vannacci G. 2018. Preharvest application of beneficial fungi as a strategy to prevent postharvest mycotoxin contamination: A review. Crop Prot 110:160-170.

Scott PM, Fuleki T and Harwig J. 1977. Patulin content of juice and wine produced from moldy grapes. J Agric Food Chem 25:434-434.

Sen L, Ocak I, Nas S and Sevik R. 2016. Effects of different drying treatments on fungal population and ochratoxin A occurrence in Sultana type grapes. Food Addit Contam Part A Chem Anal Control Expo Risk Assess 33:1444-1455.

Senthil R, Prabakar K, Rajendran L and Karthikeyan G. 2011. Efficacy of different biological control agents against major postharvest pathogens of grapes under room temperature storage conditions. Phytopathol Mediterr 50:55-65.

Serra R, Abrunhosa L, Kozakiewicz Z and Venâncio A. 2003. Black Aspergillus species as ochratoxin A producers in Portuguese wine grapes. Int J Food Microbiol 88:63-68. 
Serra R, Mendonça C and Venâncio A. 2006. Ochratoxin A occurrence and formation in Portuguese wine grapes at various stages of maturation. Int J Food Microbiol 111:S35-S39.

Serratosa MP, Lopez-Toledano A, Millan C, Medina M and Merida J. 2010. Changes of ochratoxin A in grapes inoculated with Aspergillus carbonarius and subjected to chamber-drying under controlled conditions. J Agric Food Chem 58:11907-11912.

Shemesh R, Krepker M, Nitzan N, Vaxman A and Segal E. 2016. Active packaging containing encapsulated carvacrol for control of postharvest decay. Postharvest Biol Technol 118:175-182.

Shi L, Liang Z, Li J, Hao J, Xu Y, Huang K, Tian J, He X and Xu W. 2014. Ochratoxin A biocontrol and biodegradation by Bacillus subtilis CW 14. J Sci Food Agric 94:1879-1885.

Shukla S, Kim DH, Chung SH and Kim M. 2017. Occurrence of aflatoxins in fermented food products. In Fermented Foods in Health and Disease Prevention. Frias J et al. (eds.), pp. 653-674. Academic Press, Boston.

Solfrizzo M, Avantaggiato G, Panzarini G and Visconti A. 2010. Removal of ochratoxin A from contaminated red wines by repassage over grape pomaces. J Agric Food Chem 58:317-323.

Somma S, Perrone G and Logrieco AF. 2012. Diversity of black Aspergilli and mycotoxin risks in grape, wine and dried vine fruits. Phytopathol Mediterr 51:131-147.

Sonker N, Pandey AK, Singh P and Tripathi NN. 2014. Assessment of Cymbopogon citratus (DC.) stapf essential oil as herbal preservatives based on antifungal, antiaflatoxin, and antiochratoxin activities and in vivo efficacy during storage. J Food Sci 79:1750-3841.

Sonker N, Pandey AK and Singh P. 2015. Efficiency of Artemisia nilagirica (Clarke) Pamp. essential oil as a mycotoxicant against postharvest mycobiota of table grapes. J Sci Food Agric 95:1932-1939.

Storari M, Pertot I, Gessler C and Broggini GAL. 2010. Amplification of polyketide synthase gene fragments in ochratoxigenic and nonochratoxigenic black aspergilli in grapevine. Phytopathol Mediterr 49:393-405.

Storari M, Broggini GAL, Bigler L, Cordano E, Eccel E, De Filippi R, Gessler C and Pertot I. 2012. Risk assessment of the occurrence of black Aspergilli on grapes grown in an alpine region under a climate change scenario. Eur J Plant Pathol 134:631-645.
Tancinova D, Felsoeciova S, Rybarik L, Maskova Z and Cisarova M. 2015. Colonization of grapes berries and cider by potential producers of patulin. Potravinarstvo: Scientific Journal for Food Industry 9:138-142.

Tancinova D, Maskova Z, Rybarik L, Felsoeciova S and Cisarova M. 2016. Colonization of grapes berries by Alternaria sp. and their ability to produce mycotoxins. Potravinarstvo: Scientific Journal for Food Industry 10:7-13.

Techarat S, Dachoupakan C and Cheewanun D. 2012. Growth and ochratoxin A production of black Aspergilli isolated from Thai wine grapes. As J Food Ag-Ind 5:172-182.

Terra MF, Lira NdA, Passamani FRF, Santiago WD, Cardoso MdG and Batista LR. 2016. Effect of fungicides on growth and ochratoxin A production by Aspergillus carbonarius from Brazilian wine grapes. J Food Protect 79:1508-1516.

Tjamos SE, Antoniou PP, Kazantzidou A, Antonopoulos DF, Papageorgiou I and Tjamos EC. 2004. Aspergillus niger and Aspergillus carbonarius in Corinth raisin and wine-producing vineyards in Greece: Population composition, ochratoxin A production and chemical control. J Phytopathol 152:250-255.

Trinidad AV, Ganoza FQ, Pinto VF and Patriarca A. 2015. Determination of mycotoxin profiles characteristic of Alternaria strains isolated from Malbec grapes. BIO Web of Conferences 5.

Valero A, Marín S, Ramos AJ and Sanchis V. 2005. Ochratoxin Aproducing species in grapes and sun-dried grapes and their relation to ecophysiological factors. Lett Appl Microbiol 41:196-201.

Var I, Erginkaya Z and Kabak B. 2011. Inhibition of ochratoxin A production of Aspergillus carbonarius by yeast species. Czech J Food Sci 29:291-297.

Vezzulli S, Battilani P and Bavaresco L. 2007. Stilbene-synthethase gene expression after Aspergillus carbonarius infection in grapes. Am J Enol Vitic 58:132-134.

Wang CW, Ai J, Liu YX, Lv HY, Fan ST and Yang YM. 2015. Fusarium avenaceum: A new pathogen causing Amur grape (Vitis amurensis) fruit rot in Jilin Province, China. Plant Dis 99:889-889.

Zhu C, Shi J, Jiang C and Liu Y. 2015. Inhibition of the growth and ochratoxin A production by Aspergillus carbonarius and Aspergillus ochraceus in vitro and in vivo through antagonistic yeasts. Food Control 50:125-132. 